\title{
BMJ Open Barriers to cervical cancer screening among rural women in eastern China: a qualitative study
}

\author{
Huan Yang, ${ }^{1,2}$ Shun-Ping Li, ${ }^{1,2}$ Qing Chen, ${ }^{1,2}$ Christopher Morgan ${ }^{3,4}$
}

To cite: Yang H, Li S-P, Chen Q, et al. Barriers to cervical cancer screening among rural women in eastern China: a qualitative study. BMJ Open 2019;9:e026413. doi:10.1136/ bmjopen-2018-026413

Received 31 August 2018 Revised 11 February 2019 Accepted 13 February 2019

Check for updates

(C) Author(s) (or their employer(s)) 2019. Re-use permitted under CC BY-NC. No commercial re-use. See rights and permissions. Published by BMJ.

${ }^{1}$ Shandong University, Jinan, China

${ }^{2}$ NHC Key Laboratory of Health Economics and Policy Research (Shandong University), Jinan, China

${ }^{3}$ Burnet Institute, Melbourne, Victoria, Australia

${ }^{4}$ Melbourne School of Population and Global Health, University of Melbourne, Melbourne, Victoria, Australia

Correspondence to

Dr Shun-Ping Li;

lishunping@sdu.edu.cn

\section{ABSTRACT}

Objectives To explore barriers to free cervical cancer screening among rural women in China from the perspective of women, healthcare providers and women's husbands to inform intervention planning.

Design A qualitative study framed around potential policy and practice options, drawing on the concepts of descriptive phenomenology and implementation research. Setting This study was carried out at township level within two counties in Jining Prefecture of eastern China. Participants and data collection Semi-structured in-depth interviews with 21 women and five healthcare providers, focus group discussions with nine healthcare providers and key informant interviews with four husbands of women eligible for screening.

Results Thematic analysis generated five major themes: (1) gaps in knowledge of cervical cancer and health awareness, (2) fear of cancer and screening outcomes, (3) cultural barriers including reticence for intimate examinations, (4) influence of close contacts on screening decisions and (5) inconvenience. These demonstrate key knowledge gaps challenging current community health education. Important barriers, including fear of treatment cost and the time needed for screening, were also raised. Conclusion Our study details important barriers to cervical cancer screening relating to knowledge gaps, attitudes of fear or embarrassment and the role of contacts and service models. These provide data for policy and planning to improve the screening that will decrease the incidence and mortality rates of cervical cancer in China.

\section{INTRODUCTION}

Infection with the human papilloma virus (HPV), which can be transmitted during sexual intercourse, is the most significant risk factor for cervical cancer. ${ }^{1}$ The majority of HPV infections resolve spontaneously and do not cause symptoms or disease. ${ }^{2}$ However, persistent infection with specific types of HPV (most frequently, types 16 and 18) may lead to precancerous lesions, which, if not treated, can progress to cancer 10 to 20 years later. ${ }^{3}$ Cervical cancer is a preventable and treatable disease, and screening of precancerous lesions can reduce its incidence and mortality. ${ }^{4}$ In many high-income countries, the incidence and mortality of cervical

\section{Strengths and limitations of this study}

The qualitative methods allowed for detailed and deep responses and triangulation across providers, clients and their partners.

- The findings have direct relevance to policy makers considering the development of interventions to increase uptake rate of cervical cancer screening in our setting.

- Our purposive sampling may bias our findings to those representative of women with lower educational levels and low uptake of services.

- Some social acceptability bias may have influenced focus group discussion findings, which we attempted to counterbalance with individual interview data.

- As a qualitative study, there are limits to generalisability beyond our setting.

cancer have decreased significantly because of the efforts made to detect precancerous lesions early. ${ }^{56}$ However, in low- or middle-income countries, cervical cancer remains the most common cause of cancer-related deaths among women. ${ }^{7}$

Cervical cancer is recognised as a major public health problem in China, ${ }^{8}$ both in mortality and morbidity burden, the latter causing protracted economic stress on women, heaviest in rural communities. As part of responses in 2009, a new round of deepening health system reforms intended to integrate the breast cancer and cervical cancer screening programmes in rural areas into broader national public health services. ${ }^{9}$ The government's National Cervical Cancer Screening Programme in Rural Areas launched in 221 pilot counties and a total of 11.69 million rural women between 35 and 59 years of age accessed this screening programme between 2009 and 2011. ${ }^{10}$ In one site that is the subject of our study, Jining Prefecture, free breast cancer and cervical cancer screening has been available to rural women over 35 years of age since 2011, with the upper age limit extended from 59 to 64 years in 2014, with three free screens available 
to women up until November 2017. ${ }^{4}$ However uptake rate of the free service remains very low. ${ }^{4}$

In China, a number of studies have been conducted into women's knowledge and attitudes toward cervical cancer screening and related factors, ${ }^{11-14}$ however most data have been quantitative in nature. ${ }^{12-14}$ This leaves local gaps in understanding of underlying determinants of care-seeking, including the reasons why women do not take up free care, which require more qualitative research approaches. ${ }^{1516}$ This research aimed to gain a deeper understanding of the barriers to uptake of free cervical cancer screening by rural women in Jining Prefecture, using a design that can suggest new policy and practice approaches that may be able to increase future uptake and reduce the burden of cervical cancer.

\section{METHODS}

\section{Study setting and design}

This study was conducted in Shandong Province, which is located in eastern China, with a population of more than 100 million. ${ }^{17}$ In 2016 , the gross regional product of Shandong Province amounted to CNY6803 billion (US\$1024 billion), ranking it as the third largest economy within China. ${ }^{17}$ Jining Prefecture, located in the south-west of Shandong Province with a population of 8.35 million, had the gross regional product of CNY430 billion (US $\$ 63$ billion) in $2016 .^{18}$

Our study design drew on descriptive phenomenology ${ }^{19}$ concepts of acceptability and appropriateness in health implementation research ${ }^{20}$ and was framed by options for change in policy or practice, as identified by local health managers and experts. These helped identify qualitative tools and categories of inquiry, deemed useful to understand knowledge and attitudes affecting women's and family's decision-making in relation to screening. The qualitative data collection methods included semi-structured in-depth interviews with 21 women eligible for free screening aged between 35 and 64 years and with five healthcare providers. These were supplemented by focus group discussions with healthcare providers of varying disciplines (described below) aiming to use discussion to elicit contrasting disciplinary perspectives. To gain a partner perspective, key informant interviews were conducted with husbands of women eligible for screening.

\section{Study participants and sample}

Two townships (Tangma and Xingcun) were randomly selected from within the mainly rural areas of Sishui and Yutai counties in Jining Prefecture in eastern China. Purposive sampling was used to focus research on those who were representative of women less likely to take up screening, identified by local health managers. The selection criteria included: women aged between 35 and 64 years (those eligible for free screening and at higher risk), resident in the study townships, not in formal employment and those who had either never been screened or who had failed to attend a second or third follow-up screening. Twenty-one women (10 from Xingcun and 11 from Tangma) were recruited in collaboration with township community partners. Fourteen healthcare providers (seven from Xingcun and seven from Tangma) including hospital managers, public health directors and medical practitioners whose responsibilities included contact, recording and managing data for screening and screening service provision, were purposefully selected by discipline mix. Five providers took part in semi-structured in-depth interviews and nine in two focus group discussions (four in the first and five in the second group). Four key informant interviews (two from Xingcun and two from Tangma) were conducted with screening-eligible women's husbands who were purposefully selected and were not related to the women participants. The numbers of interviews and focus group discussions were designed to enable a theoretical saturation of qualitative themes and data collection ceased at a point when no new information was being obtained (as assessed by rapid review during field operations).

\section{Data collection}

All interviews and discussions were conducted over a 1 week period in November 2017 by four researchers from Shandong University who had extensive knowledge of cervical cancer and were trained in conducting qualitative research and interviews on sensitive topics. Women participants were interviewed in healthcare institutions identified by community partners. Individual interviews in private rooms gave participants the opportunity to speak freely and comfortably. Before interviews, a short questionnaire ${ }^{4}$ including 17 items was used to assess knowledge on cervical cancer, risk factors, symptoms and the objectives and processes of cervical cancer screening. Consistent with earlier studies, responses were scored as correct (one point) and incorrect or 'do not know' (zero points), with numbers of correct scores used to categorise respondents into two groups: 'high level of knowledge' (score 9 to 17) or 'low level of knowledge' (score 0 to 8 ). ${ }^{21}{ }^{22}$ The semi-structured in-depth interviews with women used open questions in categories informed by our design, with detailed probes to deepen responses (box 1). Topics covered included

Box 1 Overview of question categories in semi-structured in-depth interviews

Knowledge of cervical cancer screening

- Have you heard about cervical cancer screening?

What do you understand about cervical cancer screening?

Why cervical cancer screening is done?

Barriers to cervical cancer screening

-Why don't you take free cervical cancer screening?

- Why do you think other women don't take free cervical cancer screening?

Suggestions for overcoming barriers

- How do you think these barriers could be overcome? 
Box 2 Overview of discussion/question categories for focus groups and provider interviews

Experience in providing screening services

- How long have you provided screening services?

What are your responsibilities for screening services?

Barriers to cervical cancer screening

Why do you think women don't take free cervical cancer screening?

Suggestions for overcoming barriers

How do you think these barriers could be overcome?

sociodemographic characteristics, screening experience, purpose of cervical cancer screening, perception of barriers to screening uptake and suggestions for overcoming barriers.

In-depth interviews and focus group discussions with providers were conducted close to the workplace and lasted approximately 30 and $45 \mathrm{~min}$, respectively. The in-depth interviews and focus group discussions guide (box 2) explored providers' experiences in providing screening services, perception of barriers to cervical cancer screening uptake for women and suggestions for overcoming barriers. Key informant interviews with husbands were conducted in their home. Interview guides included questions on their knowledge about cervical cancer and attitudes towards screening for cervical cancer and potential barriers to uptake for women.

Verbal informed consent using a standard script was obtained from all participants prior to interviews. All interviews and focus group discussions were digitally recorded. Confidentiality was ensured through using code numbers rather than names. Researchers took care to identify and reflect on any bias relating to differential status between themselves and interviewees, using introductory explanations on themselves their neutrality and the study purpose, ensuring simple comprehensible language, and maintaining careful non-judgemental listening, in order to minimise bias during the interview process. Each participant was given a vacuum beverage cup to compensate for their time commitment to the study.

\section{Data analysis}

All interviews and focus group discussions were transcribed verbatim and subjected to thematic analysis. ${ }^{23} \mathrm{We}$ analysed the data across all stakeholder groups collectively. HY collated interview and questionnaire data across all sites, ensuring consistency supervised by SL for data integrity. HY and SL jointly read all transcripts and developed themes (both pre-determined by our design and emerging), a topic index and code structure. HY, SL and QC undertook coding and thematic consolidation, with any differences discussed and resolved through consensus. These analyses were performed in Chinese and then translated into English by $\mathrm{HY}$ for further review by SL, QC and CM. Care was taken to ensure data validity in the translation of dialect and colloquialisms.
Table 1 Sociodemographic characteristics of women interviewees, $\mathrm{n}(\%)$

\begin{tabular}{|c|c|c|c|}
\hline Characteristics & Sishui $(n=10)$ & Yutai $(n=11)$ & Total $(n=21)$ \\
\hline \multicolumn{4}{|l|}{ Age (years) } \\
\hline $35 \sim 45$ & $6(60.0)$ & $0(0.0)$ & $6(28.6)$ \\
\hline $46 \sim 55$ & $3(30.0)$ & $9(81.8)$ & $12(57.1)$ \\
\hline $56 \sim 64$ & $1(10.0)$ & $2(18.2)$ & $3(14.3)$ \\
\hline \multicolumn{4}{|l|}{ Educational level } \\
\hline No school & $3(30.0)$ & $5(45.5)$ & $8(38.1)$ \\
\hline Primary school & $6(60.0)$ & $5(45.5)$ & $11(52.4)$ \\
\hline $\begin{array}{l}\text { Middle school } \\
\text { or above }\end{array}$ & $1(10.0)$ & $1(9.0)$ & $2(9.5)$ \\
\hline \multicolumn{4}{|l|}{ Marital status } \\
\hline Married & $9(90.0)$ & $11(100.0)$ & 20 (95.2) \\
\hline $\begin{array}{l}\text { Divorced or } \\
\text { widowed }\end{array}$ & $1(10.0)$ & $0(0.0)$ & $1(4.8)$ \\
\hline
\end{tabular}

Ever screened for

cervical cancer

\begin{tabular}{llll} 
Yes & $7(70.0)$ & $4(36.4)$ & $11(52.4)$ \\
No & $3(30.0)$ & $7(63.6)$ & $10(47.6)$ \\
\hline
\end{tabular}

\section{Ethical approval}

This study was approved by the Medical Ethics Committee of Medical School, Shandong University (LL-201401048), and conforms to the ethics guidelines of the Declaration of Helsinki.

\section{Patient and public involvement}

Participants were not involved in the study design and conduct, but their experiences and preferences informed the development of the research questions to generate major themes for analysis. Public involvement including community partners was involved in the recruitment process. A policy brief containing findings and implications will be provided to local policy makers and managers, and to community leaders for dissemination to study participants.

\section{RESULTS}

\section{Sociodemographic characteristics of participants}

There were no refusals of consent or dropouts during participation, with a total of 21 rural women participating. The mean age of participants was $48.7 \pm 6.4$ years, with a range from 37 to 60 years, and with more than half $(57.1 \%)$ aged between 46 and 55 years. Most participants $(95.2 \%)$ were married and most $(90.5 \%)$ had an education level of primary school or below. About half of the participants $(52.4 \%)$ had previously been screened for cervical cancer. Table 1 shows details of the characteristics of participants. The mean knowledge scores were $4.4 \pm 2.3$ (range from 0 to 10).

Among the 14 healthcare providers, the mean age was $42.6 \pm 9.0$ years and most $(64.2 \%)$ were aged between 
41 and 50 years. They had an education level of junior college and above. Most providers were medical practitioners $(50.0 \%)$. The mean age of four husbands who undertook key informant interviews was $50.7 \pm 6.3$ years and all of them were small-hold farmers.

\section{Key themes}

Thematic analysis generated five major themes: (1) gaps in knowledge of cervical cancer and health awareness, (2) fear of cancer and screening outcomes, (3) cultural barriers, (4) influence of close contacts and (5) inconvenience. Each of these is elaborated below, including quotations from participants with their identification number and age.

\section{Gaps in knowledge of cervical cancer and health awareness}

Knowledge gaps and lack of access to reliable information on cervical cancer is reported as a major barrier to women's participation in cervical cancer screening. Findings from these interviews showed that the majority of women participants had a low level of cervical cancer knowledge. Most women indicated that they had heard about cervical cancer from their friends or television, however, almost none knew that HPV infection was the cause. Some cited inaccurate information and most reported that their knowledge, especially about causes and symptoms, was speculative. For example, one reported misconception was that 'cervical cancer will never happen after menopause'. Limited knowledge seemed linked to lack of awareness of being at any personal risk of cervical cancer happening. When asked why she had not participated in cervical cancer screening, one woman stated:

I think my health is in a good condition. I've never had anything serious or any symptoms. No symptoms, no examination. We only go to the hospital when we are uncomfortable or feel sick. (Woman 11, 53 years)

One of the health provider focus groups also mentioned:

Cervix is a dumb organ. There are no symptoms nor is it typical in the early stage. It doesn't affect their work or daily life; there is even no bleeding. No symptoms, nothing at all. They don't think they are infected, so there is no need to go through the screening. (FGD 2, provider 05,41 years)

There were gaps in disease prevention understanding, as well as limited knowledge of the process, cycle, purpose and importance of screening. The importance of early screening prior to symptoms was poorly recognised. These factors were reported to limit women's acceptance of or commitment to screening, hindering or postponing their participation in cervical cancer screening.

A woman who had been notified to attend cervical cancer screening said:

I was told to do the screening yesterday. Well, I didn't want to. I thought I always have a good appetite and never feel uncomfortable. There's no point doing it. (Woman 04, 48 years)
Another woman who participated only once in cervical cancer screening stated:

I did the examination once and the doctor said I was good. So I never came back. Why bother when I'm good? (Woman 15, 55 years)

Healthcare provider viewpoints echoed this:

These women have low healthcare awareness. They wouldn't go to the hospital even if they have other common diseases. All they care about is if they could still do the housework. They don't have much understanding of medicine, so they couldn't know the significance of early screening if they got the disease. (FGD 1, provider 03,52 years)

\section{Fear of cancer and screening outcomes}

The majority of women in the interviews expressed a deep fear of cancer. Some did not want to know if they had cervical cancer; a common reason offered for why they were unwilling to attend the screening was that they did not want to learn the results. This fear extended to any form of cancer terminology. Women wanted to avoid the anxiety and distress that would be associated with being told of a cancer-related lesion:

It's a terrible disease. I'm afraid something bad might show. If I don't do the screening I wouldn't know if I had it, I will at least have a good appetite. If the results were bad, I wouldn't feel comfortable knowing that. Appetites and good sleep would be gone for sure. I would have more years to live freely if I didn't know it. (Woman 01, 37 years)

People become upset whenever they talk about cancer. In the first 2 years of the screening campaign, we couldn't put 'cancer screening' on the banner and used 'health examination' instead. People couldn't take it if they saw the word 'cancer'. (FGD 2, provider 01,47 years)

A husband also mentioned, during key informant interview:

They were all afraid they might have it. Older women would say 'why do the screening? I would be upset if I knew I had it'. (Husband 02, 63 years)

Fear of a positive screening test was also related to the financial implications. Some women with fewer economic resources reported avoiding screening because they were worried they would not have the money for treatment if they were diagnosed with the cancer, noting that at present, while screening is free of charge, treatment is not. This suggests that family finances are likely to influence their participation, with families weighing up the impact of debt against that of the disease:

We wouldn't afford the treatment even if we found out we had it, so it's better we don't do it at all. Adults need money and so do children. The money would 
be wasted if we went through the treatment and not cured. No need to spend money on a disease that can't be cured. We don't want to add burden to the family. (Woman 10, 54 years)

Two focus groups also noticed this:

People only see nearly 100000 yuan for the surgery and it's a very heavy burden. The disease would drag the already poor family into debt. They can't take it. (FGD 1, provider 02, 44 years)

There are indeed financial problems, especially for rural families. They think they don't feel anything right now, if they find out they are infected after the screening they have to go through the treatment and spend money. So it's better not to do the screening at all. (FGD 2, provider 03, 41 years)

\section{Cultural barriers}

A common report, especially among older women, was a reluctance to remove clothing or allow genital examination, especially being exposed in front of non-family members. It was mentioned by nearly all women that they felt embarrassed about this step. Informants related this to cultural norms in their rural setting, and among Chinese women more generally.

Felt like a very private part and I don't want other people to see it. That's the thought. Yes it's embarrassing. I'm too old. Don't want to be a joke. So ashamed. (Woman 09, 55 years)

When I went to the gynaecology for the screening, I went inside and the doctor told me to take off my pants, and I suddenly didn't want to do the screening. (Woman 02, 48 years)

Participants were specifically asked about willingness to accept screening by male doctors. For some participants, the gender of the service provider seemed a barrier; nearly half indicated that they would not undertake screening if performed by a male doctor.

I wouldn't go if a man was doing the examination. It's less acceptable than a woman. It's so private and men are so improper for that. (Woman 14, 41 years)

A female service provider mentioned:

They are very conservative. Some women with vaginitis go to the clinic. We tell them to take off the pants and they are embarrassed. Some even put up with the disease until they can't. So they would be more uncomfortable if male doctors are here. (Provider 01, 63 years)

\section{Influence of close contacts}

It was found that close contacts (such as mothers, sisters or neighbours) were an important factor influencing women's participation in cervical cancer screening. Knowing other people who had been screened or who had been diagnosed with cervical cancer and undertaken treatment was reported to increase participation in screening. The converse was also true, with reports that if close contacts were not willing to participate, this reduced women's acceptance of screening. This was also reported to generate clusters of women who would refuse screening.

I wouldn't know it if they (the neighbours) asked me to come along. If the others (the neighbours) don't come, I wouldn't either. It's good to have someone with you. I wouldn't come by myself. (Woman 05, 55 years)

I would for sure not come by myself. (Woman 06, 48 years)

A service provider mentioned a similar situation during the screening campaign:

We met this situation once when we were doing the screening in a town. Several women came together and they learnt they need to take off the pants. One said 'This is what it is. Forget it. Let's go'. And all of them felt reluctant and left together. It's a group mentality. (Provider 03, 43 years)

\section{Inconvenience}

Difficulty in scheduling or otherwise allocating time for screening was considered to be a significant barrier to women's participation. Many women eligible for screening work in disparate locations throughout the year may only return home at the time of Spring Festival. Such holidays are busy with limited time available for activities such as routine health checks. One working woman stated that leave is only feasible for actual illness.

I work elsewhere and only ask for leave when they have an emergency or special occasions at home. It's hard to ask for leave and I lose some salary for that. Usually I come home once a year for only 5 or 6 days. It's not enough. (Woman 21, 40 years)

Many rural people go to other places to work and don't come home often. We call them to come back but they can't. They don't get paid if they ask for leave and it's too expensive on the road. So they don't want to come back. (Provider 02, 44 years)

Women who do not travel for work also report many demands on their time including family business, childcare, housework and farming duties that are often seasonal. Lack of time for routine healthcare is reported as a barrier to cervical cancer screening either. When asked why not attend the screening, a woman who had never gone through the examination said:

I'm always busy with the kids going to school every day and housework never seems to end. Family and housework are the most important for me. So I somehow forget about it (the screening). (Woman 08, 46 years)

I tell you we farmers are pretty busy. When we are not, 
we want to do some small business to make money. So no time for examinations. (Woman 19, 56 years)

\section{DISCUSSION}

This study used qualitative tools to explore the barriers to attending cervical cancer screening among rural women in Jining Prefecture of Shandong province in eastern China. Such in-depth assessments have rarely been reported in Chinese literature. Our study identified gaps in knowledge of cervical cancer and health awareness, fear of cancer and screening outcomes, cultural barriers, the influence of close contacts and inconvenience as frequently cited barriers.

Our findings on gaps in knowledge or awareness are echoed in studies from other resource-constrained settings, with specific misconceptions and poor awareness of the benefits of routine health checks reported from diverse settings including Burkina Faso, ${ }^{24}$ Iran, ${ }^{25}$ Malawi, ${ }^{26}{ }^{27}$ Nigeria $^{28}$ and elsewhere. Reluctance to seek care in the absence of symptoms is a common theme, seen also in high-income settings such as Norway, ${ }^{29}$ and this was one of the most important constraints identified in our study. Our finding that there is very low awareness of the risks posed by cervical cancer is seen elsewhere in China. ${ }^{30}{ }^{31}$ Accessible and attractive educational products tailored to rural women are urgently needed to communicate accurate information about cervical cancer, those at risk, screening methods, treatments available and the need for regular checks.

Fear poses a significant psychological barrier to careseeking for cervical cancer screening. This includes the general fear of 'cancer' as a vicious and intractable class of disease, ${ }^{32}$ and the fear that it would not be possible to emotionally cope with a diagnosis, seen in relation to cervical cancer in our findings and in other high- middleand low-income settings. ${ }^{33-35}$ A study among Mexican women shows that women reported not attending cervical cancer screening because of fear of 'knowing,' that is, they prefer to live in hopeful uncertainty rather than facing the possibility of an unfavourable result. ${ }^{36}$ This poses a key communication challenge to community health education efforts. They must find ways to not only build knowledge of the risks of an asymptomatic disease, but also address the misconceptions and emotions aroused by cancer more generally, in order to build trust that timely screening can render cervical cancer treatable.

The influence of women's close contacts risks generating clusters of mutually-reinforcing resistance to screening, ${ }^{37}$ with partners playing a key role. ${ }^{38} 39$ This suggests some education initiatives will need to address whole communities and possibly include peer-education approaches that encourage positive health discussions among friends.

In our study, as in other resource-constrained settings, ${ }^{27}$ fears of financial catastrophe generated by high treatment costs also posed a barrier to screening. In our context this emphasises the need for health planners to understand the pragmatic choices families make when healthcare costs are seen as unaffordable. Making treatment financially accessible, for cervical cancer and many other protracted diseases, is a key challenge facing China's public health system reformers.

We found culturally based embarrassment to be a key barrier. Such associations with concepts of conservatism and modesty obstruct access to reproductive health in general and cervical cancer screening in particular in our and many other settings, ${ }^{30} 40-42$ especially when providers are male ${ }^{434}$ or women are older. ${ }^{45}$ For such communities in China and Asian populations elsewhere, ${ }^{46}$ this requires providers of screening to have high levels of cultural competence and planners to ensure sufficient numbers of female providers. Lastly, inconvenient screening services, in terms of timing and location, also posed a major barrier for the rural women in our study. This applies to those who must relocate for paid work and those whose family care duties leave little time for health screening; findings also seen in a wide range of other settings. ${ }^{33} 4748$ Delivering services at times, even holiday times, and in places where women already congregate, perhaps through mobile services, may help overcome this barrier in China, and elsewhere. ${ }^{46}$

These findings have several implications for practice, as noted above in relation to each key theme. In addition, new methods for screening ${ }^{49}$ using automated nucleic acid amplification tests may help overcome timing and location constraints by allowing more rapid screening, and may help overcome cultural distaste for vaginal examinations by allowing women to self-collect vaginal swab samples.

Our mix of data sources across women, their husbands and healthcare providers enabled triangulation of themes and identification of varying viewpoints. The qualitative methods with data saturation provided detailed and rich responses on barriers to cervical cancer screening for this group of rural women, available to inform providers and other researchers. In addition, a policy brief containing findings and implications will be provided to local policy makers and managers, and to community leaders, to inform future planning. Our study acknowledges the usual limitations of qualitative research, our purposeful sample may over-represent women with lower educational levels and low uptake of services, and the peer effect in focus group discussions may have influenced providers to give answers that they perceive to be more socially acceptable. As a qualitative study, our findings relate primarily to our study setting and our recommendations should be tested with larger studies.

\section{CONCLUSION}

In summary, our study details important barriers to cervical cancer screening in terms of gaps in knowledge, fear of cancer and screening outcomes, cultural embarrassment, the influence of close contacts and inconvenience. We hope policy makers and planners can make 
use of these findings to improve education and service delivery for screening that will decrease the incidence and mortality rates of cervical cancer in China.

Acknowledgements We would like to acknowledge and thank all community partners who assisted with data collection and recruitment of participants and the study participants for their time and contribution to this study. This work was supported by China Medical Board Open Competition Grant [Grant number CMB14195]. Responsibility for any remaining errors lies solely with the authors.

Contributors HY designed the study, completed the data collection and analyses and wrote the manuscript. S-PL designed the study, collected and analyzed the data and edited the manuscript. QC designed the study, collected and analyzed the data. CM helped design the study, supported interpretation of findings and edited the manuscript. All authors have read and approved the final manuscript.

Funding This work was supported by China Medical Board Open Competition Grant [Grant number CMB14-195]. Responsibility for any remaining errors lies solely with the authors.

Competing interests None declared.

Patient consent for publication Not required

Ethics approval The study was approved by the Medical Ethics Committee of Medical School, Shandong University (LL-201401048).

Provenance and peer review Not commissioned; externally peer reviewed.

Data sharing statement № additional data are available.

Open access This is an open access article distributed in accordance with the Creative Commons Attribution Non Commercial (CC BY-NC 4.0) license, which permits others to distribute, remix, adapt, build upon this work non-commercially, and license their derivative works on different terms, provided the original work is properly cited, appropriate credit is given, any changes made indicated, and the use is non-commercial. See: http://creativecommons.org/licenses/by-nc/4.0/.

\section{REFERENCES}

1. Acharya Pandey R, Karmacharya E. Cervical cancer screening behavior and associated factors among women of Ugrachandi Nala, Kavre, Nepal. Eur J Med Res 2017;22:32.

2. WHO. Comprehensive cervical cancer prevention and control: a healthier future for girls and women. Gevena: World Health Organization, 2013.

3. de Sanjose S, Quint WG, Alemany L, et al. Human papillomavirus genotype attribution in invasive cervical cancer: a retrospective cross-sectional worldwide study. Lancet Oncol 2010;11:1048-56.

4. Liu T, Li S, Ratcliffe J, et al. Assessing knowledge and attitudes towards cervical cancer screening among rural women in Eastern China. Int J Environ Res Public Health 2017;14:967.

5. Haesebaert J, Lutringer-Magnin D, Kalecinski J, et al. French women's knowledge of and attitudes towards cervical cancer prevention and the acceptability of HPV vaccination among those with 14 - 18 year old daughters: a quantitative-qualitative study. BMC Public Health 2012;12:1034.

6. Giles M, Garland S. A study of women's knowledge regarding human papillomavirus infection, cervical cancer and human papillomavirus vaccines. Aust N Z J Obstet Gynaecol 2006;46:311-5.

7. Louie KS, de Sanjose S, Mayaud P. Epidemiology and prevention of human papillomavirus and cervical cancer in sub-Saharan Africa: a comprehensive review. Trop Med Int Health 2009;14:1287-302.

8. Gu C, Chan CW, Twinn S. How sexual history and knowledge of cervical cancer and screening influence Chinese women's screening behavior in mainland China. Cancer Nurs 2010;33:445-53.

9. Chen W, Zheng R, Zhang S, et al. Report of cancer incidence and mortality in China, 2010. Ann Trans/ Med 2014;2:61.

10. Di J, Rutherford S, Wu J, et al. Knowledge of Cervical Cancer Screening among Women across Different Socio-Economic Regions of China. PLoS One 2015;10:e0144819.

11. Jia Y, Li S, Yang R, et al. Knowledge about cervical cancer and barriers of screening program among women in Wufeng County, a high-incidence region of cervical cancer in China. PLoS One 2013;8:e67005

12. Tang T. Investigation on status quo of cognitive, attitude and behavior of women toward cervical cancer screening and analysis of its related factors. Chinese And Foreign Medical Research 2016;03:68-9.
13. Liu L, Xu J, Yang C, et al. Investigation on status quo of cognitive of 1208 outpatients toward cervical cancer screening and analysis of its related factors. Practical Clinical Journal of Integrated Traditional Chinese and Western Medicine 2016.

14. Zhou W, Shan H, Qi J, et al. Investigation on status quo of cognitive of 1200 women of childbearing age toward cervical cancer and analysis of its related factors. Maternal and Child Health Care of China 2017;18:4510-2.

15. Li SP, Zheng ZY, Meng QY, et al. Barriers to tuberculosis care for drug users in two provinces of China: a qualitative study. Int $J$ Tuberc Lung Dis 2013;17:1358-63.

16. Pope C, Mays N. Reaching the parts other methods cannot reach: an introduction to qualitative methods in health and health services research. BMJ 1995;311:42-5.

17. China Statistical Yearbook. 2017 http://www.stats.gov.cn/tjsj/ndsj/ 2017/indexch.htm (Accessed 9 Mar 2018).

18. Shandong Statistical Yearbook. 2017 http://www.stats-sd.gov.cn/tjnj/ nj2017/indexch.htm (Accessed 9 Mar 2018).

19. Denzin NK, Lincoln YS. Handbook of qualitative research. Thousand Oaks, CA, US: Sage Publications, Inc, 1994.

20. Peters DH, Tran NT, Adam T. Implementation research in health: a practical guide. Alliance for Health Policy and Systems Research: World Health Organization, 2013.

21. Bansal AB, Pakhare AP, Kapoor N, et al. Knowledge, attitude, and practices related to cervical cancer among adult women: A hospitalbased cross-sectional study. J Nat Sci Biol Med 2015;6:324-8.

22. Ahmed SA, Sabitu K, Idris SH, et al. Knowledge, attitude and practice of cervical cancer screening among market women in Zaria, Nigeria. Niger Med J 2013;54:316-9.

23. Braun V, Clarke V. Using thematic analysis in psychology. Qual Res Psychol 2006;3:77-101.

24. Compaore S, Ouedraogo CMR, Koanda S, et al. Barriers to Cervical Cancer Screening in Burkina Faso: needs for patient and professional education. J Cancer Educ 2016;31:760-6.

25. Bayrami R, Taghipour A, Ebrahimipour H. Personal and sociocultural barriers to cervical cancer screening in Iran, patient and provider perceptions: a qualitative study. Asian Pac J Cancer Prev 2015;16:3729-34.

26. Fort VK, Makin MS, Siegler AJ, et al. Barriers to cervical cancer screening in Mulanje, Malawi: a qualitative study. Patient Prefer Adherence 2011:5:125-31.

27. Ndejjo R, Mukama T, Kiguli J, et al. Knowledge, facilitators and barriers to cervical cancer screening among women in Uganda: a qualitative study. BMJ Open 2017;7:e016282.

28. Isa Modibbo F, Dareng E, Bamisaye P, et al. Qualitative study of barriers to cervical cancer screening among Nigerian women. BMJ Open 2016;6:e008533.

29. Gele AA, Qureshi SA, Kour P, et al. Barriers and facilitators to cervical cancer screening among Pakistani and Somali immigrant women in Oslo: a qualitative study. Int $J$ Womens Health 2017;9:487-96.

30. Gu C, Chan CW, Twinn S, et al. The influence of knowledge and perception of the risk of cervical cancer on screening behavior in mainland Chinese women. Psychooncology 2012;21:1299-308.

31. Twinn S, Shiu AT, Holroyd E. Women's knowledge about cervical cancer and cervical screening practice: a pilot study of Hong Kong Chinese women. Cancer Nurs 2002;25:377-84.

32. Vrinten $C$, McGregor LM, Heinrich M, et al. What do people fear about cancer? A systematic review and meta-synthesis of cancer fears in the general population. Psychooncology 2017;26:1070-9.

33. Nolan J, Renderos TB, Hynson J, et al. Barriers to cervical cancer screening and follow-up care among Black Women in Massachusetts. J Obstet Gynecol Neonatal Nurs 2014:43:580-8.

34. Mupepi SC, Sampselle CM, Johnson TR. Knowledge, attitudes, and demographic factors influencing cervical cancer screening behavior of Zimbabwean women. J Womens Health 2011;20:943-52.

35. Agurto I, Bishop A, Sánchez G, et al. Perceived barriers and benefits to cervical cancer screening in Latin America. Prev Med 2004;39:91-8.

36. Marván ML, Ehrenzweig Y, Catillo-López RL. Knowledge about cervical cancer prevention and psychosocial barriers to screening among Mexican women. J Psychosom Obstet Gynaecol 2013;34:163-9

37. Cunningham MS, Skrastins E, Fitzpatrick R, et al. Cervical cance screening and HPV vaccine acceptability among rural and urban women in Kilimanjaro Region, Tanzania. BMJ Open 2015;5:e005828.

38. Winkler J, Bingham A, Coffey P, et al. Women's participation in a cervical cancer screening program in northern Peru. Health Educ Res 2008;23:10-24.

39. Akinyemiju TF. Socio-economic and health access determinants of breast and cervical cancer screening in low-income countries: analysis of the World Health Survey. PLoS One 2012;7:e48834. 
40. Daley E, Alio A, Anstey EH, et al. Examining barriers to cervical cancer screening and treatment in Florida through a socio-ecological lens. J Community Health 2011;36:121-31.

41. Ghebre RG, Sewali B, Osman S, et al. Cervical cancer: barriers to screening in the Somali community in Minnesota. $J$ Immigr Minor Health 2015;17:722-8.

42. Kwok C, White K, Roydhouse JK, et al. Facilitators and barriers related to cervical cancer screening: a qualitative study. J Immigr Minor Health 2011;13:1076.

43. Maar M, Burchell A, Little J, et al. A qualitative study of provider perspectives of structural barriers to cervical cancer screening among first nations women. Womens Health Issues 2013;23:e319-25.

44. Williams MS, Amoateng P. Knowledge and beliefs about cervical cancer screening among men in Kumasi, Ghana. Ghana Med J 2012;46:147-51.
45. Byrd TL, Chavez R, Wilson KM. Barriers and facilitators of cervical cancer screening among Hispanic women. Ethn Dis 2007;17:129-34.

46. Lu M, Moritz S, Lorenzetti D, et al. A systematic review of interventions to increase breast and cervical cancer screening uptake among Asian women. BMC Public Health 2012;12:413.

47. Markovic M, Kesic V, Topic L, et al. Barriers to cervical cancer screening: a qualitative study with women in Serbia. Soc Sci Med 2005;61:2528-35.

48. Foliaki S, Matheson A. Barriers to cervical screening among Pacific women in a New Zealand Urban Population. Asian Pac J Cancer Prev 2015;16:1565-70.

49. Toliman P, Badman SG, Gabuzzi J, et al. Field evaluation of Xpert HPV Point-of-care test for detection of human papillomavirus infection by use of self-collected vaginal and clinician-collected cervical specimens. J Clin Microbiol 2016;54:1734-7. 